$\xi=-1$

\title{
Mathematical Modeling of the Resistance of Pulling out Steel Bars from High Strength Concrete
}

\author{
Yevgenij Babych $^{1 *}$, Sergij Filipchuk ${ }^{2}$, Oleksiy Fenko ${ }^{3}$ \\ ${ }^{I}$ National University Of Water And Environmental Engineering, Ukraine \\ ${ }^{2}$ National University Of Water And Environmental Engineering, Ukraine \\ ${ }^{3}$ Poltava National Technical Yuri Kondratyuk University, Ukraine \\ *Corresponding Author E-Mail: E.M.Babich@Nuwm.Edu.Ua
}

\begin{abstract}
The article gives the results of the experimental researches of the bond between steel and high strength concrete. According to these results the mathematical model was built to define the boundary stresses of the bond between steel and concrete on their contact surface. The analysis of the impact of the specific factors on the boundary stresses of the bond between steel and concrete was carried out.
\end{abstract}

Keywords: bond, concrete, strength, steel.

\section{Introduction}

The bond between steel and concrete is an important quality of the reinforced concrete which defines its carrying capacity, hardness and crack resistance, and depends on a great number of factors: strength of concrete, type and diameter of a steel bar, length of making bars in concrete, depth of concrete cover, nature of load, long processes, granulometric composition of the mixture, nature of the aggregate, hardening conditions, position of the steel bars during concrete casting and others. In relation to this the safety of anchoring a steel bar in reinforced concrete structures also depends on a number of factors which define its bond with concrete. Because of a great number of influencing factors the task of investigating the bond between steel and concrete is complicated but at the same time very crucial [1].

Today a considerable extending in the use area of reinforced concrete structures especially in fortifications demands the application of high strength concrete of C70, C80 and higher classes. [2,3].

Based on the above, the aim of the research is to find out the peculiarities of the bond between a steel bar and high strength concrete, to determine the corresponding calculated characteristics of the bond strength.

As it is known that concrete is an elastic-plastic material which is characterized by curvilinear diagrams of a mechanical state, it is necessary to choose the plans for receiving quadratic dependencies (quadratic mathematical model). The matrix of the Box-Behnken design corresponds to the demands above. [4].

\section{Research Methods}

In the planned experiment the impact factors (independent variables) are accepted as: $x_{1}$ - diameter of the bars; $x_{2}-$ length of anchoring a steel bar (length of making bars in concrete); $x_{3}$ - depth of concrete cover (table 1).
All factors have a high degree of control that makes it possible to choose the given level of variation. For the diameter of the bars on the basic level of planning (0) diameter $16 \mathrm{~mm}$, and on the lower (-1) and top (+1) levels - correspondingly 12 i $20 \mathrm{~mm}$ (interval of variation equals $4 \mathrm{~mm}$ ) are accepted. These diameters of the bars are mostly spread for concrete reinforcing.

Table 1: Conditions of planning of the experiment

\begin{tabular}{|c|c|c|c|c|c|}
\hline \multicolumn{2}{|c|}{ Factors } & \multicolumn{2}{|c|}{ Levels of variation } & \multirow{2}{*}{$\begin{array}{c}\text { Interval of } \\
\text { variation }\end{array}$} \\
\hline $\begin{array}{c}\text { Natural look } \\
\text { Diameter of bars, } \\
d, \text { mm }\end{array}$ & $x_{1}$ & 12 & 16 & 20 & 4 \\
\hline $\begin{array}{c}\text { Length of anchor- } \\
\text { age, } l_{b}\end{array}$ & $x_{2}$ & $5 d$ & $10 d$ & $15 d$ & $5 d$ \\
\hline $\begin{array}{c}\text { Depth of concrete } \\
\text { cover, } c\end{array}$ & $x_{3}$ & $1 d$ & $2 d$ & $3 d$ & $1 d$ \\
\hline
\end{tabular}

Along with the main samples there produced 6 test cubes in the size of $150 \times 150 \times 150 \mathrm{~mm}$ to define the cube strength of concrete at 28 days and in the period of test samples, 6 prisms in the size of $150 \times 150 \times 600 \mathrm{~mm}$ to define prism strength of concrete and initial module of elasticity at 28 days and in the time of test samples.

Average cube strength of concrete at 28 days made up $f_{c m, \text { cube }}=$ $70,4 \mathrm{MPa}$ accordingly. Average prism strength of concrete for accepted class of the concrete amounted $f_{\text {cm,prism }}=58,8 \mathrm{MPa}$.

In our researches we used a steel bar of A500C class and 12, 16 and $20 \mathrm{~mm}$ in diameter, it is most commonly used for concrete reinforcing. Index Rhema for these bars made up $f_{R}=0,070 ; 0,075$ та 0,071 accordingly, that corresponds to average values providing needed bond with concrete.

The basic test samples were produced in the form of concrete prisms of square cross section, sides of which equal $15 \mathrm{~cm}$, and the height corresponds to the planned length of anchorage. Steel bars were located in the prisms in such a way that their longitudinal axis matched together, and parts of bars cantilevering out of prisms allowed to fasten in the grip of the hydraulic press on the one side, and on the other (free) side of the bars to measure their 
displacement relative to the end of the prisms (fig. 1). All the parameters of the samples were taken relative to the matrix of the experimental design.

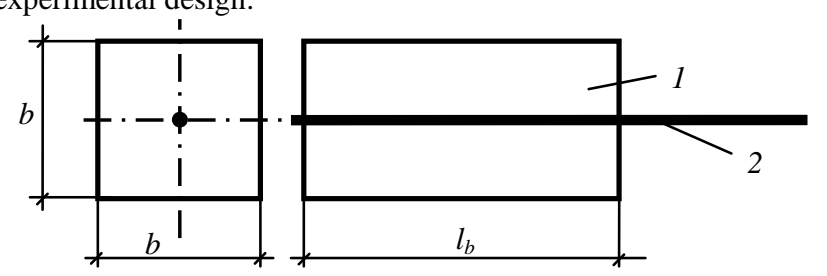

Fig. 1: Constructive scheme of the test samples [3]. 1 - concrete prism; 2 - steel bar.

In each point of the design there produced three twin samples, and on the basic level - six samples. Besides there made concrete samples in the form of standard cubes and prisms to define the strength features of the concrete under pressure, as well as in the form of prisms to define the strength of the concrete when stretching. According to the design altogether 18 basic samples were tested. Moulding of the samples was made in the wooden forms where ahead of time the steel bars had been placed.

The researches of the bond between steel and concrete were carried out by means of pulling out the bars from the concrete prisms using a special reverse device in the tensile hydraulic machine UIM-50. Pulling out the bars was made by steps equal to $\Delta F=$ $(0,5 \ldots 1,0) \mathrm{\kappa N}$.

The boundary state of the bond between steel and concrete was taken as the force in the bar $F_{u}$, when displacement of its free end relative to the end of the prism accounted $\delta_{u}=0,1 \mathrm{~mm}$ or the splitting of the prism at $\delta<0,1 \mathrm{~mm}$ had happened (fig. 2).

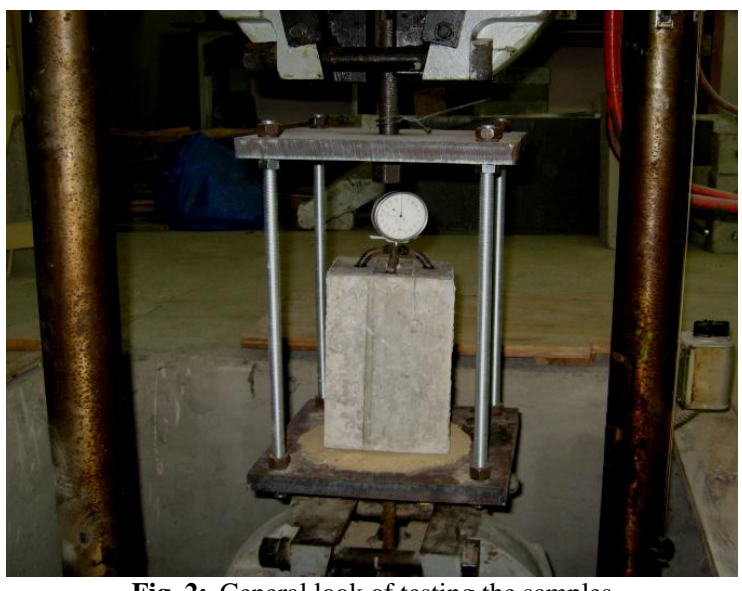

Fig. 2: General look of testing the samples

In the boundary state we defined maximum shearing stresses (bond stress) which are medium in length for every sample using a formula

$f_{b i}=F_{u i} /\left(\pi \cdot d \cdot l_{b}\right)$

where $f_{b i}$ - boundary medium in length bond stresses of $i$ sample on the contact surface of a bar with concrete;

$F_{u i}$ - breaking force of $i$ sample in the boundary state;

$d$-diameter of a bar;

$l_{b}$ - length of making a bar in concrete (length of anchorage of a bar).

Boundary medium shearing stresses appearing on the contact surface of a bar with concrete $f_{b}$, which were defined by the formula (1), may be called as bond strength of a steel bar with concrete. The criterion of the strength is displacement of the end of a bar in concrete to $0,1 \mathrm{~mm}$ and more or splitting the concrete (Fig. 3) .

\section{Results of the Researches}

While testing the basic samples, for each of them in the boundary state there defined the breaking forces $F_{u}$, and according to their values we defined the values of the boundary stresses of the bond between bars and concrete on their contact $f_{b i}$, as well as their average values in each point on the $\operatorname{design} f_{b m}$ (table 2.).

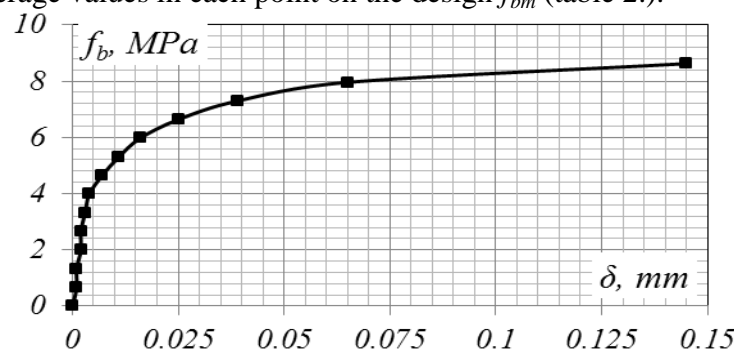

Fig. 3: Displacement of a free end of a bar depending on shearing stresses

On the basic level medium maximum bond stresses accounted $f_{b m}$ $=11,22 \mathrm{MPa}$ based on the results of testing six samples.

Complete quadratic equations of regressions to describe maximum bond stresses based on the equation (2) are given as follows [4]:

$f_{b}=b_{0}+b_{1} x_{1}+b_{2} x_{2}+b_{3} x_{3}+b_{11} x_{1}^{2}+b_{22} x_{2}^{2}+b_{33} x_{3}^{2}+b_{12} x_{1} x_{2}+$

$+b_{13} x_{1} x_{3}+b_{23} x_{2} x_{3}$

where $b_{0}, b_{i}, b_{i i}, b_{i j}$ - absolute term of the regression equation and coefficients of linier, quadratic factors and interaction factors.

Coefficients of regression equations $b_{0}, b_{i}, b_{i i}, b_{i j}$ for three level of the Box-Behnken design are defined statistically by formulas:

$b_{0}=\frac{\sum_{i=1}^{n_{0}} f_{b 0}}{n_{0}} ;$

$b_{i}=T_{3}\left(i f_{b)}\right.$

$b_{i i}=T_{4}\left(i i f_{b}\right)+T_{5}\left(\sum_{i=1}^{3}\left(i i f_{b}\right)-T_{6}\left(0 f_{b}\right) ;\right.$

$b_{i j}=T_{6}\left(i j f_{b}\right)$

where $f_{b 0}$-initial parameters on the zero level;

$n_{0}$ - number of researches on the zero level (number of zero points);

$i, j$-numbers of researches (in researches $i=1 \ldots 3 ; j=1 \ldots 3$ );

$f_{b}$ - initial parameters (experimental data);

$T_{2} ; T_{3} ; T_{4} ; T_{5} ; T_{6}$ - calculated values of the parameters defined for specific designs with the help of the methods of the mathematical statistics.

Absolute coefficient defined by the formula (2) appeared to be equal $b_{0}=11,22 \mathrm{MPa}$ based to the research results in the zero points. Other coefficients were defined using formulas (3) - (6), where calculated parameters to define these coefficients were found by the following formulas:

$\left(i f_{b}\right)=\sum_{1}^{N} x_{i} f_{b m}$

Table 2: Matrix of the Box-Behnken design and initial experimental data

\begin{tabular}{|c|c|c|c|c|c|c|c|}
\hline \multirow{2}{*}{\begin{tabular}{c} 
Points $\begin{array}{c}\text { of } \\
\text { design }\end{array}$ \\
\cline { 2 - 8 }
\end{tabular}} & \multicolumn{2}{|c|}{ Matrix of planning } & \multicolumn{4}{|c|}{ Initial parameters, $f_{b}, \mathrm{MPa}$} \\
\hline 1 & +1 & $x_{2}$ & $x_{3}$ & $f_{b 1}$ & $f_{b 2}$ & $f_{b 3}$ & $f_{b m}$ \\
\hline 2 & +1 & 0 & 8.75 & 9.61 & 9.97 & 9.44 \\
\hline 3 & -1 & +1 & 0 & 7 & 8.91 & 7.16 & 7.69 \\
\hline 4 & -1 & -1 & 0 & 7.5 & 6.32 & 8.84 & 7.55 \\
\hline
\end{tabular}




\begin{tabular}{|c|c|c|c|c|c|c|c|}
\hline 5 & +1 & 0 & +1 & 11.62 & 11.46 & 11.46 & 11.51 \\
\hline 6 & +1 & 0 & -1 & 10.03 & 10.9 & 10.19 & 10.37 \\
\hline 7 & -1 & 0 & +1 & 11.94 & 11.48 & 13.6 & 12.34 \\
\hline 8 & -1 & 0 & -1 & 9.62 & 9.75 & 9.75 & 9.71 \\
\hline 9 & 0 & +1 & +1 & 11.94 & 10.78 & 9.53 & 10.75 \\
\hline 10 & 0 & +1 & -1 & 9.53 & 9.55 & 10.53 & 9.87 \\
\hline 11 & 0 & -1 & +1 & 10.57 & 10.54 & 10.44 & 10.52 \\
\hline 12 & 0 & -1 & -1 & 9.12 & 8.7 & 9 & 8.94 \\
\hline \multirow{2}{*}{13} & \multirow{2}{*}{0} & \multirow{2}{*}{0} & \multirow{2}{*}{0} & 11.19 & 10.47 & 11.31 & \multirow{2}{*}{11.22} \\
\cline { 5 - 7 } & & & & & & &
\end{tabular}

Notes. 1 . In the points $1-12$ of the design researches are done by three. 2.In the point 13 of the design 6 researches (basic level) are done ).

$$
\begin{aligned}
& \left(i i f_{b}\right)=\sum_{1}^{N} x_{i}^{2} f_{b m} ; \\
& \left(i j f_{b}\right)=\sum_{1}^{N} x_{i} x_{j} f_{b m} ; \\
& \left(0 f_{b}\right)=\sum_{1}^{N} x_{0} f_{b m},
\end{aligned}
$$

where $N$ - number of the points of the design.

Parameter calculations by formulas (7) - (10) are summarized in Table 5. For the three- level Box-Behnken design the calculated values of the parameters $T$ are taken as follows [2]: $T_{2}=0,1667$; $T_{3}=0,125 ; T_{4}=0,25 ; T_{5}=-0,0028 ; T_{6}=0,25$. Found by the formulas $(3)-(6)$ the values of coefficients in the regression equations taking into account the data in Table 5 and formulas (7) (10) are given in Table 3. For example:

$$
\begin{aligned}
& b_{1}=T_{3}\left(i f_{b}\right)=0.125 \cdot(-0.16)=-0.02 ; \\
& b_{11}=T_{4}\left(i i f_{b}\right)+T_{5}\left(\sum_{i=1}^{3}\left(i i f_{b}\right)-T_{2}\left(0 f_{b}\right)=0.25 \cdot 78.2-\right. \\
& -0.0028(78.2+74.34+84.01)-0.1667 \cdot 118.28=-0.83 ; \\
& b_{12}=T_{6}\left(i j f_{b}\right)=0.25 \cdot(-0.27)=-0.07 .
\end{aligned}
$$

According to the value of the regression coefficients we can judge the degree of an impact of the appropriate factor. Coefficients are considered to be significant if the calculated value of Student's $t-$ test appeared to be more than tabular, set up depending on the given level of significance and number of degrees of freedom.

To define the calculated value of Student's $t$ - test for each coefficient of the regression equation it is necessary to define the meansquare deviation of an initial parameter and mean-square error. In the theory of planned experiments mean-square deviation is allowed to be defined according to the number of researches in the zero points $n_{0}$ and to use it for the whole experiment. In this case the variation of the research results in the other points of the design is not taken into account, but it may differ from the variation in the zero points. It is especially true for reinforced concrete elements and in particular concrete. That is why it is advisable to estimate the significance of the coefficient $b_{0}$ by the research results in the zero points, and all others - in all points of the design. Considering the given mean-square deviation of the research results in the zero points $S_{\left\{f_{b 0}\right\}}$ and in other points of the design $S_{\left\{f_{b i}\right\}}$ we can define accordingly by formulas:

$$
\begin{aligned}
& S_{\left\{f_{b 0}\right\}}=\sqrt{\frac{\sum_{1}^{n_{0}}\left(f_{b 0 i}-f_{b 0 m}\right)^{2}}{n_{0}-1} ;} \\
& S_{\left\{f_{b i}\right\}}=\sqrt{\frac{\sum_{1}^{N} \sum_{1}^{r}\left(f_{b i}-f_{b m}\right)^{2}}{N(r-1)}},
\end{aligned}
$$

where $n_{0}$ - number of researches in the zero points $\left(n_{0}=6\right)$;
$N$ - number of design rows except zero points $(N=12)$

$r$ - number of researches in a row $(r=3)$.

In order to define the mean-square deviations by formula (12) reconstruction variances were first defined according to the rows of the design in a tabular form.

The mean-square deviations are defined by the formula:

$S_{\left\{f_{b i}\right\}}=\sqrt{\frac{\sum S_{\left\{f_{b}\right\}}^{2}}{N(r-1)}}=\sqrt{\frac{12.82}{12(3-1)}}=0.731$

To find theoretical values of Student's $t$ - test for each coefficient of the regression equation it is necessary to define the meansquare errors by formulas:

$$
\begin{aligned}
& S_{\left\{b_{0}\right\}}=T_{7} \cdot S_{\left\{f b_{0}\right\}} ; \quad S_{\{b i\}}=T_{8} \cdot S_{\left\{f b_{i}\right\}} ; \\
& S_{\left\{b_{0}\right\}}=T_{9} \cdot S_{\left\{f b_{i i}\right\}} ; \quad S_{\left\{b_{i j}\right\}}=T_{10} \cdot S_{\left\{f b_{i j}\right\}}
\end{aligned}
$$

where $T_{7}, T_{8}, T_{9}, T_{10}$ - coefficients which are taken equal $T_{7}=$ 0,5774; $T_{8}=0,3536 ; T_{9}=0,5204 ; T_{10}=0,5$ for the three-level Box-Behnken design.

By the formula (13) values of the mean-square errors turned out to be equal:

$$
\begin{aligned}
& S_{\left\{b_{0}\right\}}=0,5774 \times 0,308=0,178 ; \\
& S_{\{b 1\}}=S_{\{b 2\}}=S_{\{b 3\}}=0.3536 \times 0.731=0.258 ; \\
& S_{\{b 11\}}=S_{\{b 22\}}=S_{\{b 33\}}=0.5204 \times 0.731=0.38 ; \\
& S_{\{b 12\}}=S_{\{b 13\}}=S_{\{b 23\}}=0.5 \times 0.731=0.365 ;
\end{aligned}
$$

Table 3: Coefficient values of the regression equations

\begin{tabular}{|c|c|c|c|c|c|c|c|c|c|}
\hline$b_{0}$ & $b_{1}$ & $b_{2}$ & $b_{3}$ & $b_{11}$ & $b_{22}$ & $b_{33}$ & $b_{12}$ & $b_{13}$ & $b_{23}$ \\
\hline & - & & & & & & & & \\
11.2 & 0.0 & 0.6 & 0.7 & - & - & & - & - & - \\
2 & 2 & 2 & 8 & 0.83 & 1.79 & 0.62 & 0.07 & 0.37 & 0.17 \\
\hline
\end{tabular}

By the formula (11) there calculated the values of the mean-square deviation for the research in the zero points that occurred equal $S_{\left\{f_{b 0}\right\}}=0,308 \times$ The calculated values of Student's $t$ - test for each coefficient regression equation were found by the formulas [4]:

$t_{\left\{b_{0}\right\}}=\frac{\left|b_{0}\right|}{S_{\left\{b_{0}\right\}}} ; \quad t_{\{b i\}}=\frac{\left|b_{i}\right|}{S_{\{b i\}}} ; \quad t_{\{b i i\}}=\frac{\left|b_{i i}\right|}{S_{\{b i i\}}} ; \quad t_{\{b i j\}}=\frac{\left|b_{i j}\right|}{S_{\{b i j\}}}$

Tabular values of Student's $t_{m}$ - test can be defined for the level of significance 0,05 depending on the number of the degrees of freedom. For the coefficients $b_{0}$ the number of the degrees of freedom makes up $f_{\{b\}}=n_{0}-1=6-1=5$, but for other coefficients $f_{\{b\}}=N(r-1)=12(3-1)=24$. Accordingly tabular Student's $t_{m^{-}}$ test is: for coefficients $b_{0} \quad \underline{t_{m}}=2,57$, for other coefficients $-\underline{t}_{\underline{m}}=$ 2,06 .

Comparing the values of the calculated and tabular tests we come to the conclusion that coefficients $t_{b 12} \mathrm{i}_{t_{b 23}}$ cannot be considered in the equation. For the coefficients under the quadratic factors the values of the calculated coefficients are less than tabular, but under quadratic factors it is not recommended to neglect coefficients of the regression equations [4].

Table 4: Value of Student's $t$ - test

\begin{tabular}{|l|l|l|l|l|l|l|l|l|l|}
$t_{b 0}$ & $t_{b 1}$ & $t_{b 2}$ & $t_{b 3}$ & $t_{b 11}$ & $t_{b 22}$ & $t_{b 33}$ & $t_{b 12}$ & $t_{b 13}$ & $t_{b 23}$ \\
\hline
\end{tabular}
\begin{tabular}{c|c|c|c|c|c|c|c|c|c|}
$t_{b 0}$ & $t_{1}$ & $t_{22}$ & $t_{b 3}$ & $t_{11}$ & $t_{b 22}$ & $t_{b 33}$ & $t_{b 12}$ & $t_{b 13}$ & $t_{b 23}$ \\
\hline 63.03 & 0.08 & 2.39 & 3.01 & 2.18 & 4.72 & 1.64 & 0.19 & 1.02 & 0.48 \\
\hline
\end{tabular} Ultimately the regression equations, which can be believed to be mathematical models to define the boundary stresses of the bond between concrete and steel bars on their contact surface, can be written in the following way according to the research results: 


$$
f_{b}=11.22+0.62 x_{2}+0.78 x_{3}-0.83 x_{1}^{2}-1.79 x_{2}^{2}+0.62 x_{3}^{2}-0.37 x_{1} x_{3}
$$

The obtained regression equation adequately describes the results of the experimental researches, as the calculated value of Fisher's $F$ - ratio test is less than the tabular value. The calculated value of Fisher's $F$-ratio test were found by the formula:

$F_{p}=\frac{S_{\left\{f_{b}\right\}}^{2}}{S_{a d}^{2}}$

where $S_{\left\{f_{b}\right\}}^{2}$ - reconstruction variance of the initial parameter which is evaluated by the formula:

$S_{\left\{f_{b}\right\}}^{2}=\frac{\sum_{1}^{N} \sum_{1}^{r}\left(f_{b i}-f_{b m}\right)^{2}}{N(r-1)}$,

where $\sum_{1}^{N}$ - amount per matrix column;

$\sum_{1}^{r}$ - amount per matrix rows;

$S_{a d}^{2}-$ variance of adequacy, defined by the formula

$S_{a d}^{2}=\frac{r}{N-m} \sum_{1}^{N}\left(f_{b, \text { theoret }}-f_{b m}\right)^{2}$,

where $m$-a number of significant coefficients in regression equation $(m=7)$;

$f_{b, \text { theoret }}$ - calculated value of the initial parameter, which is defined by the formula 15 ;

$f_{b m}$ - initial parameter according to results of the experimental researches.

Reconstruction variance of the initial parameter (boundary stresses of the bond) taking into account the data of Table 7 by formula (18) is $S_{\left\{f_{b}\right\}}^{2}=0.534$.

Variance of the adequacy by the formula (19) appeared to be $S_{a d}^{2}=$ 1,06. To formula (16) calculated value of Fisher's $F$-test equals $F_{p}=1,98$. Tabular coefficient of 0,95 with a greater degree of freedom than 24 and less than 6 equals $F_{m}=2,55$. As a tabular test is larger than the calculated one, a formed regression equation adequately describes the obtained experimental data.

Equation adequacy can be confirmed by other statistical indicators (Table 9). So the average ration of the experimental values of the boundary stresses of the bond between steel bars and concrete to the theoretical values, defined by the formula (15), amounts $f_{b m} / f_{b, \text { theoret }}=0,997$. The mean-square deviations are 0,04 , as for coefficients of variation they are 0,04 , that is less than permissible normalized indicator for the concrete 0,135 .

Therefore, the obtained regression equation (15) can be used to analyze an impact of instances on the boundary stresses on the surface of concrete and steel, as well as to normalize the boundary stresses of the bond.

Table 5: Statistical estimate of adequacy of regression equations

\begin{tabular}{|c|c|c|c|}
\hline $\begin{array}{c}\text { Point of de- } \\
\text { sign }\end{array}$ & $f_{b m}$ & $f_{b, \text { theoret }}$ & $f_{b m} / f_{b, \text { theoret }}$ \\
\hline 1 & 9.44 & 9.13 & 1.035 \\
\hline 2 & 7.69 & 8.03 & 0.958 \\
\hline 3 & 9.58 & 9.30 & 1.030 \\
\hline 4 & 7.55 & 7.93 & 0.952 \\
\hline 5 & 11.51 & 11.77 & 0.978 \\
\hline 6 & 10.37 & 10.22 & 1.015 \\
\hline 7 & 12.34 & 11.81 & 1.045 \\
\hline
\end{tabular}

\begin{tabular}{|c|c|c|c|}
\hline 8 & 9.71 & 10.26 & 0.946 \\
\hline 9 & 10.75 & 11.45 & 0.939 \\
\hline 10 & 9.87 & 9.89 & 0.998 \\
\hline 11 & 10.52 & 10.21 & 1.030 \\
\hline 12 & 8.94 & 8.65 & 1.033 \\
\hline \multicolumn{2}{|l|}{ Average value } & 0.997 \\
\hline \multicolumn{2}{|l|}{ Mean-square deviation } & 0.040 \\
\hline \multicolumn{2}{|l|}{ Coefficient of variation } & 0.040 \\
\hline
\end{tabular}

\section{Analysis of an Impact of Factors on the Bond}

The analysis of regression equation structures shows the absence of the linier impact of the bar diameter on the boundary stresses of the bond $f_{b}$, that can be explained by the fact that according to geometrical characteristics the bars have practically the same index Rhema. $f_{b}$., is also influenced by the bar diameter, as it is quadratic factor and interaction factor.

The obtained mathematical model allows analyzing the impact of factors, that were investigated on the boundary stresses on the contact surface of steel and concrete. Herewith, the values of code $x_{i}$ depending on the accepted natural values $X_{i}$ are defined as follows:

$X_{i}=\frac{X_{i}-X_{i 0}}{\Delta X_{i}}$

where $X_{i 0}$ - natural value of $i$ - factor in the zero point;

$\Delta X_{i}$ - variation interval of $i$ - factor.

For diameter of bars $d=12 \mathrm{~mm}$ the character of the bond stresses $f_{b i}$ is curvilinear because of the side of the concrete cover $c$. This character is preserved with the length of anchoring $l_{b}=5 d, 10 d$ and $15 d$ (fig.4.). It should be noted that the minimum value of the bond stress is for the length of anchoring $l_{b}=5 d$, and the maximum one for $l_{b}=10 d$. So when the size of the concrete cover is $c=2 d$ and the length of anchoring is $l_{b}=5 d$, bond stress accounts $f_{b}=7,98 \mathrm{MPa}$, but when $l_{b}=10 d$, it is $f_{b}=10,39 \mathrm{MPa}$.
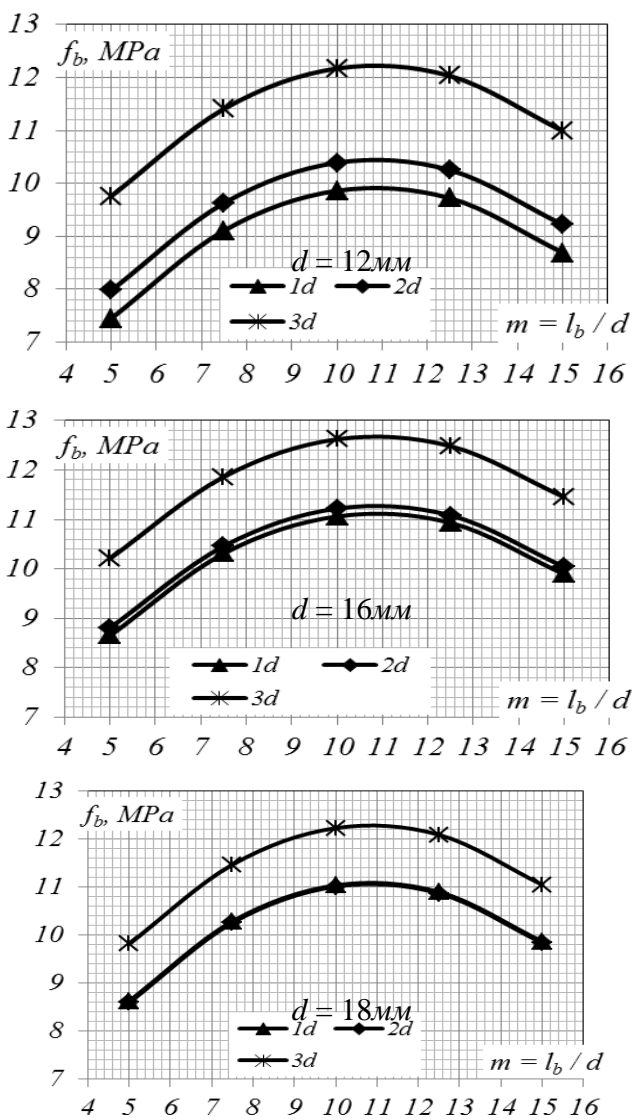


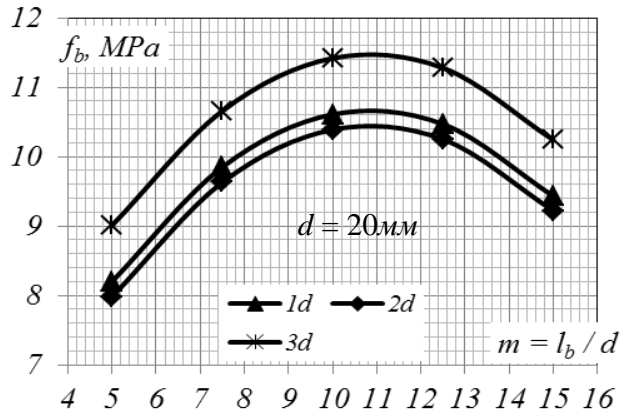

Fig. 4: Impact of the length of the bar anchoring on the boundary bond stresses on the contact surface with concrete

The same character of dependence occurs for the bars of $16,18 \mathrm{i}$ $20 \mathrm{~mm}$ in diameter, but for the bars of $16 \mathrm{~mm}$ in diameter the value of bond stresses $f_{b}$ is more and makes up $f_{b}=8,81 \mathrm{MPa}$ at $l_{b}$ $=5 d$ and $f_{b}=11,22 \mathrm{MPa}$ at $l_{b}=10 d$. The greatest bond stress $f_{b}$ for the concrete is for the length of anchoring at $l_{b}=10 d$, that is, as for standard concrete, for which the rules of designing reinforced concrete structures regulate this minimum value of making steel bars in concrete out of the inner edge of the free support [5, 6].

The analysis of the results of the experimental researches speaks that the depth of the concrete cover has a significant impact on the boundary bond stresses (fig. 5). So with the concrete cover $c=$ $36 \mathrm{~mm}$ (bars are situated along the axis of the concrete prism) for the steel bar $d=12 \mathrm{~mm}$ maximum bond stresses accounts $f_{b}=$ $12,17 \mathrm{MPa}$, and at $c=18(c=1,5 d)$ and $c=12 \mathrm{~mm}(c=1,0 d)$ respectively $f_{b}=10,39$ i $9,86 \mathrm{MPa}$. A similar relative reduction of the bond stresses is observed in samples with steel bars of 16 i 20 $\mathrm{mm}$ in diameter. Thus, the maximum bond occurs at the largest concrete cover, while the minimum bond being at the least.
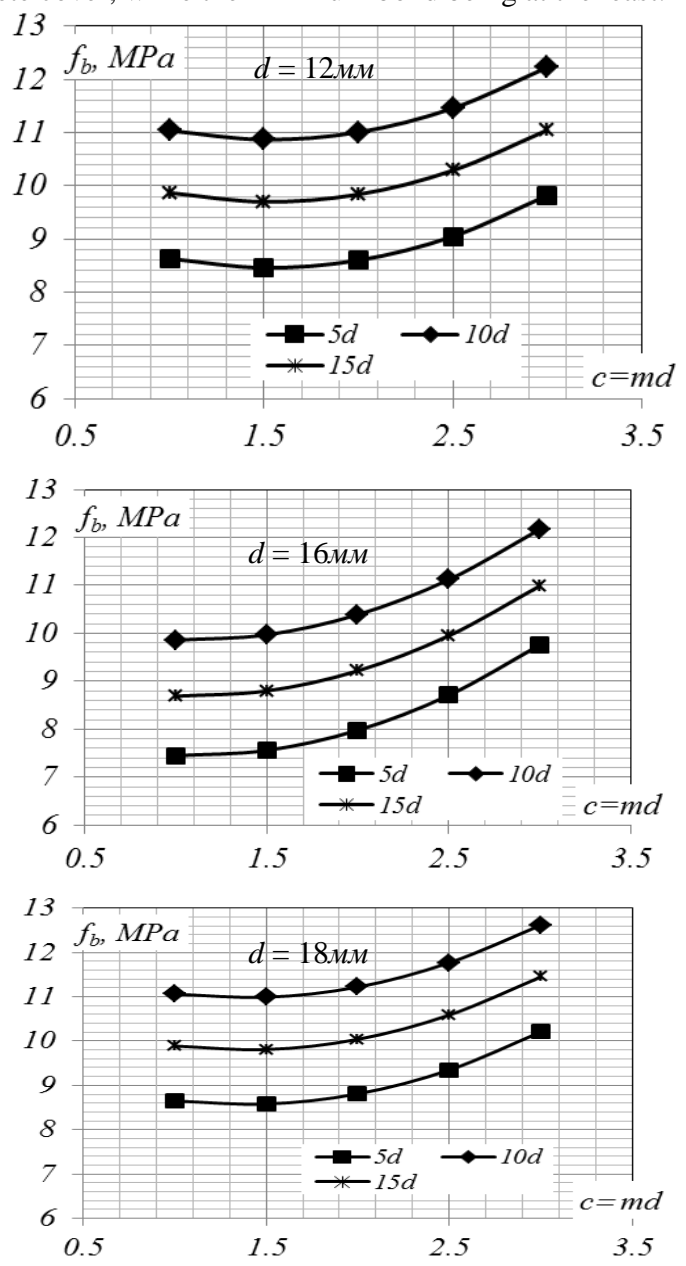

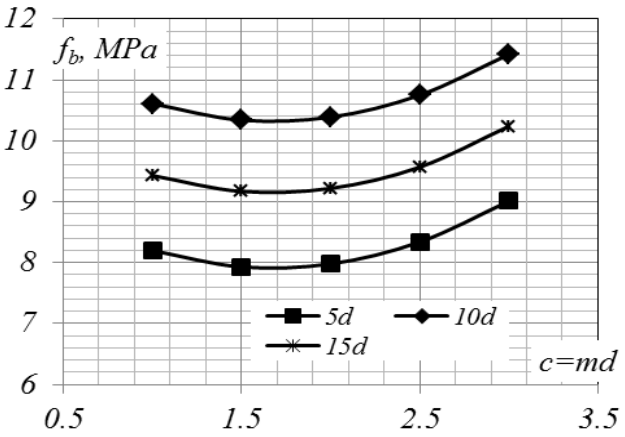

Fig. 5: Impact of the size of the concrete cover on the boundary bond stresses on the contact surface with concrete

The character of destruction of the samples also depends on the depth of the concrete cover (fig. 6). At $c=3 d$ the destruction occurred in three-four planes with the appearing of cracks on the lateral area, the prism was divided into separate elements. However, in the prisms with the concrete cover $l_{b}=10 d$ there was a stiffening of the steel bar and appearance of a split in the direction toward all sides. At $c=1,5 d$ cracks were developed within the concrete cover, but immediately before the complete destruction in the direction toward the cheeks. In the samples with $c=1 d$, the destruction took place in the plane which crossed the concrete cover. It should be noted that the longitudinal cracks were formed along the longitudinal actions of the bars as a result of the wedging moment of the transverse actions, located at the angle to the direction of pulling out the bars.

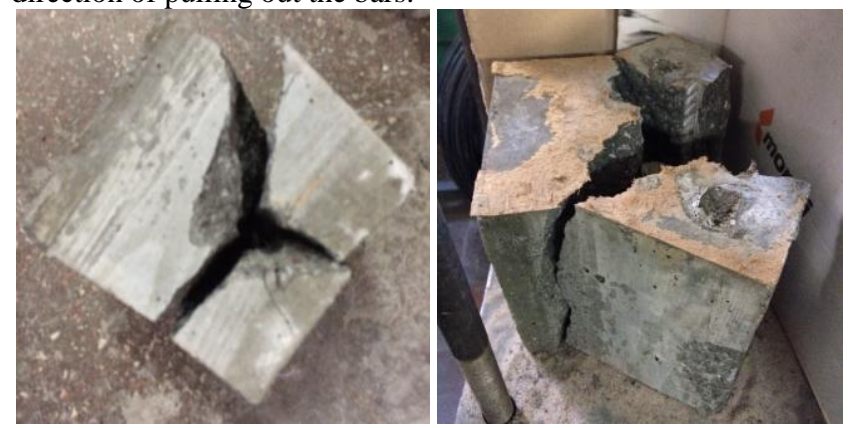

Fig. 6: Character of destruction of the samples with steel bars of $16 \mathrm{~mm}$ in diameter

\section{Conclusion}

According to the results of the planned experiment the regression equation (15) can be used to analyze an impact of the specific factors on the boundary stresses on the surface of concrete and a steel bar, as well as to normalize the boundary stresses of the bond. The adequacy of the mathematical models of bonds to the experimental data has been proved by the statistical methods.

It has been experimentally proved that the depth of the concrete cover substantially affects the maximum stresses of the bond between concrete and steel and the character of destructing prisms.

\section{References}

[1] Dvorkin L.J., Babich E.M., ZHitkovs'kij V.V., Bordyuzhenko O.M., Filipchuk S.V.,Kochkar'ov D.V., Kovalik I.V., Koval'chuk T.V., Skripnik M.M. Visokomicni shvidkotverdnuchi betoni ta fibro betoni - Rivne: NUVGP, 2017. $331 \mathrm{~s}$

[2] Mekhanichni harakteristiki shvidkotverdnuchih visokomicnih betoniv. / E.M. Babich, V.C. Babich, S.V. Filipchuk, D.V. Kochkar'ov // Resursoekonomni materiali, konstrukcii, budivli ta sporudi: Zbirnik naukovih prac'. - Rivne: NUVGP, 2016. - Vipusk 32. - S. $114-120$.

[3] Zcheplennya $\mathrm{z}$ betonom armaturi serpopodibnogo profilyu ta iii ankeruvannya v zginal'nih zalizobetonnih elementah: Monografiya / E. M. Babich, V. E. Babich, O. E. Polyanovs'ka .- Rivne: «Volins'ki oberegi», 2017. - $160 \mathrm{~s}$. 
[4] Dvorkin L.J. Rozv'yazuvannya budivel'no-tekhnologichnih zadach metodami matematichnogo planuvannya eksperimentu / L.J. Dvorkin, O.L. Dvorkin, V.V. ZHitkovs'kij. - Rivne: NUVGP, 2011. $-174 \mathrm{~s}$.

[5] Babich V. E. Doslidzhennya zcheplennya armaturi $\mathrm{z}$ betonom zalezhno vid tovshchini zahisnogo sharu / V. C. Babich, O.C. Polyanovs'ka, P. V. Demchuk // Resursoekonomni materiali,konstrukciï, budivli ta sporudi: Zbirnik naukovih prac'. - Rivne: NUVGP, 2014. - Vipusk 28.- S. $105-111$.

[6] Zalezhnist' micnosti zcheplennya pinobetonu $\mathrm{z}$ kompozitnoyu skloplastikovoyu armaturoyu vid dovzhini ankeruvannya. / Filipchuk S.V., Karvan B.V., CHapyuk O.S., Grishkova A.V.// Suchasni tekhnologiï ta metodi rozrahunkiv u budivnictvi: Zbirnik naukovih prac'. - Luc'k: LNTU, 2016. - Vipusk 5. - S. 301 - 307 